\title{
Monitoring Program for nursing homes: Brazilian Municipal Proposal Based on International Standards
}

Dr. Idiberto Jose Zotarelli Filho, MSc, Ph.D ${ }^{1}$

${ }^{1}$ Affiliation not available

May 19, 2020

\begin{abstract}
Introduction: On March 11, 2020, the World Health Organization (WHO) declared the coronavirus outbreak (COVID-19) to be pandemic. By March 16, 2020, 139 countries were affected. In this situation, the Scientific Societies decided to prepare this Contingency Plan to guide the response of health services. 4,088,848 COVID-19 cases and 283,153 deaths were confirmed worldwide. Recent data presented by the Ministry of Health in Brazil show that 177,589 cases of coronavirus and 72,597 recovered people have already been registered. However, nursing homes usually are not counted in these statistical data, as people usually die in the Istitution. Thus, developing a monitoring program in medical services, such as in nursing homes for eldery people (NHE) with ideal care for possible patients infected with COVID-19, is essential to increase the protection of the most vulnerable, as well as professionals of health. Objective: To present the monitoring program of the Nursing homes in the city of São José do Rio Preto/SP, by Faceres Medica School, as an important strategy to identify, control and allocate patients infected by COVID-19. Methods: All the NHE registered in the city council were raised, with data such as head nurse name, number of beds available and number of inpatients. According to the program's action plan, telephone calls was made daily by trained medical students with a professor tuition to all institutions and information was provided by the head nurse. Thus, when a resident or employee has symptoms, he was removed and tested for SARS-CoV-2. Subsequently, epidemiological surveillance was communicated and the case was monitored. Final Considerations: According to the world literature, elderly patients with COVID- 19 are more likely to progress to severe disease. Therefore, extensive measures to reduce the transmission of COVID-19 from person to person are being implemented to control the current outbreak. The monitoring program at the NHE proposed in the present study aims to collaborate in this regard, especially to the most vulnerable.
\end{abstract}

\section{Toufic Anbar Neto1, André Luciano Baitello2, Patrícia Maluf Cu- ry1, Cristiane Spadacio1, João Pedro Daher Anbar1, Isabela Da- her Anbar1, Amena Alcântara Ferraz Cury2, Maria Raquel Moré de Mattos2, Soraya Andrade Pereira2, Idiberto José Zotarelli Fil- ho1 Aldenis Albaneze Borim3}

1 FACERES - Medical School of Sao Jose do Rio Preto/SP, Brazil.

2 CITY HALL. Secretariat of Health of Sao Jose do Rio Preto/SP, Brazil.

3 FAMERP- School of Medicine of Sao Jose do Rio Preto/SP, Brazil. 
*Corresponding Author: Dr. Idiberto José Zotarelli Filho, MSc, Ph.D. Faceres Medical School of Sao Jose do Rio Preto, e-mail address: m.zotarelli@gmail.com.

\section{ABSTRACT}

Introduction: On March 11, 2020, the World Health Organization (WHO) declared the coronavirus outbreak (COVID-19) to be pandemic. By March 16, 2020, 139 countries were affected. In this situation, the Scientific Societies decided to prepare this Contingency Plan to guide the response of health services. 4,088,848 COVID-19 cases and 283,153 deaths were confirmed worldwide. Recent data presented by the Ministry of Health in Brazil show that 177,589 cases of coronavirus and 72,597 recovered people have already been registered. However, nursing homes usually are not counted in these statistical data, as people usually die in the Istitution. Thus, developing a monitoring program in medical services, such as in nursing homes for eldery people (NHE) with ideal care for possible patients infected with COVID-19, is essential to increase the protection of the most vulnerable, as well as professionals of health. Objective: To present the monitoring program of the Nursing homes in the city of São José do Rio Preto/SP, by Faceres Medica School, as an important strategy to identify, control and allocate patients infected by COVID-19. Methods:. All the NHE registered in the city council were raised, with data such as head nurse name, number of beds available and number of inpatients. According to the program's action plan, telephone calls was made daily by trained medical students with a professor tuition to all institutions and information was provided by the head nurse. Thus, when a resident or employee has symptoms, he was removed and tested for SARS-CoV-2. Subsequently, epidemiological surveillance was communicated and the case was monitored. Final Considerations: According to the world literature, elderly patients with COVID- 19 are more likely to progress to severe disease. Therefore, extensive measures to reduce the transmission of COVID-19 from person to person are being implemented to control the current outbreak. The monitoring program at the NHE proposed in the present study aims to collaborate in this regard, especially to the most vulnerable.

Keywords: COVID-19. Monitoring Program. Nursing Home Elderly.

\section{Introduction}

In January 2020, Chinese authorities identified a new virus in the family Coronaviridae as the cause of several cases of pneumonia of unknown etiology. The outbreak was initially confined to the city of Wuhan but later spread outside Chinese borders [1]. On March 11, 2020, World Health Organization (WHO) declared the coronavirus outbreak (SARS-CoV-2) that causes COVID-19 disease to be pandemic. By March 16, 2020, 139 countries were affected [2]. Due to this, Medical Scientific Societies decided to elaborate a Contingency Plan to guide the response of the health services [3]. The objectives of this plan was to estimate the magnitude of the problem and to identify human and material resources needs. Many medical services in the world created tools to program strategies to contain the disease [4], however, most of them were focused in Intensive Care services. In the world, 4,088,848 cases of COVID-19 (and 283,153 deaths, raising daily in a geometric progression, were confirmed by May 12, 2020 [5]. The Pan American Health Organization (PAHO) and WHO has being providing technical support to Brazil and other countries in preparing and responding to the COVID-19 outbreak [6]. Recent data presented by the Ministry of Health in Brazil showed that 177,589 
cases of coronavirus and 72,597 people recovered have already been registered [7]. According to data from the European Center for Disease Prevention Control, from December 31, 2019, until March 16, 2020, the disease spread to 139 countries and 16,741 cases, including 6,507 deaths. In this context, mortality of elderly patients is higher [8], estimated at 7,8\% in people aged over 80 compared with to $0.0016 \%$ in children aged 9 and under [9]. Scientific societies consider the need to develop a contingency plan in an attempt to mitigate this new disease, contributing with the authorities, health managers, and doctors a technical document that addresses all aspects related to the identification of seriously needed patient care needs patients facing a new SARS-CoV virus pandemic, for realistic and comprehensive planning of medical services [10]. In addition, developing a monitoring program in medical services, such as NHE with ideal care for possible patients infected with COVID-19, is essential to increase the protection of the most vulnerable, as well as health professionals. In this context, telemedicine outlines an important strategy in response to the COVID-19 pandemic. Therefore, the present study aimed to present a telemedicine NHE monitoring program in the city of São José do Rio Preto / SP, by the Faceres Medical School, as an important strategy to identify, control, and allocate patients infected by COVID-19.

\section{Methods}

Monitoring program for influenza/respiratory syndromes of NHEAll the NHE registered in the city council were raised, with data such as head nurse name, number of beds available and number of inpatients. According to the program's action plan, telephone calls was made daily by trained medical students with a professor tuition to all institutions and information was provided by the head nurse. Thus, when a resident or employee has symptoms, he was removed and tested for SARS-CoV-2. Subsequently, epidemiological surveillance was communicated and the case was monitored. The contingency plan model created by FACERES Medical School comprises two phases, as shown in Table 1 below.

Table 1. Proposed Monitoring Program at the LTCIE.

PHASE 1: First calls

1) Ask for the best times to call.

2) Who will communicate the data (can be a health professional or administrative)?

3) Request if you have any cell phone that can receive a WhatsApp call.

PHASE 2: Routine call

Daily call of the FACERES monitoring team: Ask if any resident has symptoms of flu-like syndrome or res] 5) If there are no residents or employees with symptoms, the FACERES team will briefly report on the rep If any resident or employee has symptoms: The FACERES team will ask the NHE to call the physician res

In this sense, the present monitoring program in NHE addresses the main symptoms of COVID-19 infection that appear after an incubation period of approximately 5.2 days, depending on the age and status of the patient's immune system [11]. The most common symptoms at the onset of COVID-19 disease are fever, cough and fatigue, while other symptoms include sputum production, headache, hemoptysis, diarrhea, dyspnea, and lymphopenia. The clinical features revealed by a computed tomography scan of the chest can present as pneumonia, as well as increased serum viral load of SARS-CoV-2 RNA (RNAaemia), acute respiratory distress syndrome, acute cardiac injury, and incidence of liquid crystal opacities [11] (Figure 1). Essa figura não me parece adequada ao artigo. O foco do artigo é analisar uma estratégia de monitoramento por telemedicina de idosos institucionalizados. Podemos discutir de tirar e teríamos mais espaço para outros pontos da introdução que podem ser melhor desenvolvidos.Figure 1. Main systemic and respiratory disorders caused by COVID-19. 


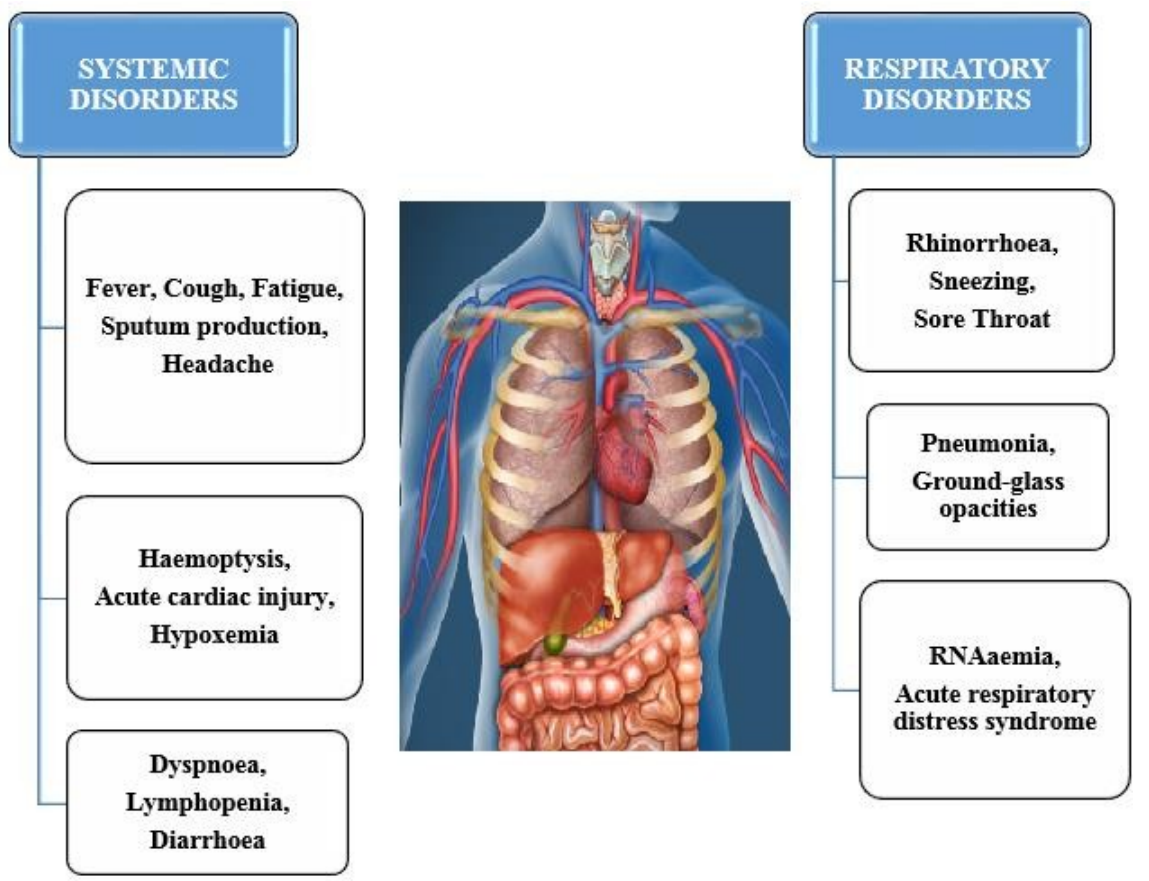

In this scenario, based on international standards [3,4], the present program recommends NHE to conduct training for its employees with the use of training materials such as infographics, posters, etc. It is recommended that each NHE should organize training sessions with at least the following contents: COVID19 epidemiology, impact on activity, transmission, COVID-19 diagnosis, individual protection measures, personal protective equipment (PPE), and isolation. Furthermore, because the coronavirus is transmitted mainly by respiratory droplets greater than $5 \mu \mathrm{m}$ and by direct contact with the secretions of infected patients, the present monitoring program also recommends the following preventive measures in accordance with international standards, as shown in Table 2.

Table 2. Recommendations for preventive measures [3,4].

Precautions for contact and transmission of droplets for the treatment of all patients, both suspected and c Strict hand hygiene.

All professionals must be trained in the use of PPE.

Patients with a suspected infection should be isolated in a single room.

The generated waste can be considered as class III waste.

Protective gloves and clothing.

Respiratory protection.

Eye and face protection.

PPE: Personal protective equipment

\section{Discussion}

Coronavirus disease 2019 (COVID-19), which causes severe respiratory diseases such as pneumonia and lung failure, was first reported in Wuhan, capital of Hubei, China. The etiological agent of COVID-19 has been confirmed as a new coronavirus, now known as severe acute respiratory syndrome coronavirus 2 (SARS- 
CoV-2), which probably originates from zoonotic coronaviruses, such as SARS-CoV, which appeared in 2002 Some months after the first report, SARS-CoV-2 spread to China and the world, reaching a pandemic level [8]. Due to the virulence of SARS-CoV-2, it is imperative to develop strategies such as the present NHE monitoring program to contain the spread of the virus. In this sense, a study confirmed the incidence of COVID-19 in 1099 elderly patients aged 60 years or over, 27.0\% of whom had severe disease [10]. Another study looked at 4021 confirmed cases, and the results showed that $1,052(26.2 \%)$ were 60 years or older. In terms of mortality, the mortality rate of patients aged 60 years or older $(5.3 \%)$ is significantly higher than that of patients younger than 60 years (1.4\%) [11]. The characteristics of multisystem disease coexisting in the elderly lead to complicated and complex diseases and affect each other. Elderly patients are prone to organ dysfunction, including gastrointestinal bleeding, kidney failure, intravascular coagulation, or deep vein thrombosis [12-14]. Residents of a NHE in the context of COVID-19 call for close monitoring of changes and appropriate decision-making. However, access to specialization in geriatrics is generally limited by the lack of geriatricians, general practitioners, and/or nurses with advanced clinical skills, leading to potentially preventable hospitalizations. Therefore, it is imperative to develop, implement and evaluate innovative care models adapted to the context, guided by nurses, that support NHE in improving their quality of care and reducing hospitalizations, investing in effective clinical leadership, geriatric experience, and assistance coordination [15]. As Health System wordwide is not supporting all patients due to pandemy, a special attention should be given to eldery people. In NHE, there are healthy eldery lonely people but also very compromised patients, that could be considered as palliative care patients. Thus, to differentiate these patients would help to plan different treatment and strategies for them. As an example, a health service in the USA has developed a strategy to implement a palliative care response that incorporates conventional capacity, contingency capacity, and crisis capacity [16]. This strategy has also been adopted in several countries and focuses on the main content areas, including the identification and meeting of care goals, the treatment of moderate and severe symptoms, and support for family members $[17,18]$.

\section{Conclusion}

Extensive measures to reduce the transmission of COVID-19 from person to person are being implemented to control the current outbreak. The monitoring program at NHE proposed in the present study aims to collaborate in this regard, especially to the most vulnerable. Special attention and efforts to protect or reduce transmission should be applied to these populations of the elderly and health professionals.

\section{Acknowledgements and Funding}

We thank all the nursing homes, medical students and the health professional who collaborate to implement this program.

\section{Declaration of Potential Conflict of Interest}

The authors declare no conflict of interest.

\section{References}

1. Li J-Y, You Z, et al. The epidemic of 2019-novel-coronavirus (2019-nCoV) pneumonia and insights for emerging infectious diseases in the future. Microbes Infect 2020 In press, journal pre-proof Available online 20 February 2020.

2. Xu XW, Wu XX, Jiang XG, et al. Clinical findings in a group of patients infected with the 2019 novel coronavirus (SARS-Cov-2) outside of Wuhan, China: retrospective case series. BMJ 2020;368:m606. doi:10.1136/bmj.m606.

3. Sedes PR, Sanz MÁB, Saera MAB, RodríguezRey LFC, Ortega ÁC, González MC, López CH, Santos ED, Barcena AE, Mera MJF, Cano JCI, Delgado MCM, Estalella GM, Raimondi N, Gas ORI, 
Oviedo AR, Pío ERS, Álvarez JT, Raurell M; Junta directiva de la SEMICYUC; Junta directiva de la SEMICYUC; Junta directiva de la SEEIUC. Contingency Plan for the Intensive Care Services for the COVID-19 pandemic. Enferm Intensiva. 2020 Apr 3. pii: S1130- 2399(20)30037-7. doi: 10.1016/j.enfi.2020.03.001.

4. Rascado Sedes P, Ballesteros Sanz MA, Bodí Saera MA, Carrasco Rodríguez-Rey LF, Castellanos Ortega A, Catalán González M, López CH, Díaz Santos E, Escriba Barcena A, Frade Mera MJ, Igeño Cano JC, Martín Delgado MC, Martínez Estalella G, Raimondi N, Roca I Gas O, Rodríguez Oviedo A, Romero San Pío E, Trenado Álvarez J; Junta directiva de la SEMICYUC; Junta directiva de la SEEIUC. Contingency plan for the intensive care services for the COVID-19 pandemic. Med Intensiva. 2020 Apr 23. pii: S0210-5691(20)30095-4. doi: 10.1016/j.medin.2020.03.006.

5. WHO-World Health Organization-COVID-19. Disponível em:https://www.who.int/docs/defaultsource/coronaviruse/getting-workplace-ready- for-covid-19.pdf.

6. Organização Pan-Americana da Saúde (OPAS). Disponível em:https://www.paho.org/es/documentos/enfermedadpor-coronavirus-covid-19- and-hiv-asuntos-acciones-claves

7. Ministério da Saúde do Brasil. Disponível em: https://coronavirus.saude.gov.br/

8. Guan W.J., Ni Z.Y., Zhong N.S., et al. Clinical characteristics of 2019 novel coronavirus infection in China. Med Rxiv, 2020, [Epub ahead of print]. https://doi.org/10.1101/2020.02.06.20020974.

9. Mahase E. Covid-19: death rate is $0.66 \%$ and increases with age, study estimates. BMJ. 2020 Apr 1;369:m1327. doi: 10.1136/bmj.m1327.

10. Yang Y., Lu Q.B., Liu M.J., et al. Epidemiological and clinical features of the 2019 novel coronavirus outbreak in China. Med Rxiv, 2020, [Epub ahead of print]. DOI: https://doi.org/10.1101/2020.02.10.20021675.

11. Liu Y, Gayle AA, Wilder-Smith A, et al. The reproductive number of COVID-19 is higher compared to SARS coronavirus. J Travel Med2020 [Epub ahead of print]. doi:10.1093/jtm/taaa021.

12. Liu K, Chen Y, Lin R, Han K. Clinical features of COVID-19 in elderly patients: A comparison with young and middle-aged patients. J Infect. 2020 Mar 27. pii: S0163- 4453(20)30116-X. doi: 10.1016/j.jinf.2020.03.005.

13. Fumagalli S, Salani B, Gabbani L, Mossello E, Ungar A. Covid-19 cases in a no- Covid-19 geriatric acute care setting. A sporadic occurrence? Eur J Intern Med. 2020 Apr 30. pii: S0953-6205(20)30179-5. doi: 10.1016/j.ejim.2020.04.058.

14. Ahn DG, Shin HJ, Kim MH, Lee S, Kim HS, Myoung J, Kim BT, Kim SJ. Current Status of Epidemiology, Diagnosis, Therapeutics, and Vaccines for Novel Coronavirus Disease 2019 (COVID-19). J Microbiol Biotechnol. 2020 Mar 28;30(3):313-324. doi: 10.4014/jmb.2003.03011.

15. Zúniga F, De Geest S, Guerbaai RA, Basinska K, Nicca D, Kressig RW, Zeller A, Wellens NIH, De Pietro C, Vlaeyen E, Desmedt M, Serdaly C, Simon M. Strengthening Geriatric Expertise in Swiss Nursing Homes: INTERCARE Implementation Study Protocol. J Am Geriatr Soc. 2019 Oct;67(10):21452150. doi: 10.1111/jgs.16074. Epub 2019 Jul 18.

16. Fausto J, Hirano L, Lam D, Mehta A, Mills B, Owens D, Perry E, Curtis JR. Creating a Palliative Care Inpatient Response Plan for COVID-19-The UW Medicine Experience. J Pain Symptom Manage. 2020 Mar 31. pii: S0885-3924(20)30176-7. doi: 10.1016/j.jpainsymman.2020.03.025.

17. Raurell-Torredà M, Martínez-Estalella G, Frade-Mera MJ, Carrasco Rodríguez-Rey LF, Romero de San Pío E. Reflections arising from the COVID-19 pandemic. Enferm Intensiva. 2020 Apr 3. pii: S1130-2399(20)30038-9. doi: 10.1016/j.enfi.2020.03.002.

18. Rothan HA, Byrareddy SN. The epidemiology and pathogenesis of coronavirus disease (COVID-19) outbreak. J Autoimmun. 2020 May;109:102433. doi: 10.1016/j.jaut.2020.102433. Epub 2020 Feb 26. 